\title{
Invited Article Foreword
}

In this issue, the Invited Articles section is comprised of the article "Steiner Tree Approximation via Iterative Randomized Rounding", by Thomas Rothvoss, Jaroslaw Byrka, Fabrizio Grandoni, and Laura Sanità. This article was selected from the 42nd ACM Symposium on Theory of Computing (STOC 2010), held in Cambridge, MA, June 6-8, 2010. I thank the Program Committee of STOC 2010 and the PC Chair, Leonard J. Schulman, for their help in selecting this invited article. I am also grateful to JACM Associate Editor Éva Tardos for her editorial work on this article.

Editor-in-Chief

(C) 2013 ACM 0004-5411/2013/02-ART5 $\$ 15.00$

DOI : http://dx.doi.org/10.1145/2432622.2432627 